OPEN ACCESS

Edited by:

Penghao Wang,

Murdoch University, Australia

Reviewed by:

Weiping Kong,

Chinese Academy of Sciences, China

Zitong Yu,

Kansas State University,

United States

*Correspondence:

Chen-Yang Wang

xmzxwang@163.com

Wei Feng

fengwei78@126.com

Specialty section:

This article was submitted to Technical Advances in Plant Science,

a section of the journal

Frontiers in Plant Science

Received: 06 October 2020 Accepted: 08 March 2021

Published: 30 March 2021

Citation:

Zhang $H-Y$, Liu M-R, Feng Z-H, Song $L$, Li X, LiU W-D, Wang C-Y and Feng W (2021) Estimations of Water Use Efficiency in Winter Wheat Based on Multi-Angle Remote Sensing.

Front. Plant Sci. 12:614417. doi: 10.3389/fpls.2021.614417

\section{Estimations of Water Use Efficiency in Winter Wheat Based on Multi-Angle Remote Sensing}

\author{
Hai-Yan Zhang, Meng-Ran Liu, Zi-Heng Feng, Li Song, Xiao Li, Wan-Dai Liu, \\ Chen-Yang Wang* and Wei Feng*
}

State Key Laboratory of Wheat and Maize Crop Science, National Engineering Research Center for Wheat, Henan Agricultural University, Zhengzhou, China

Real-time non-destructive monitoring of water use efficiency (WUE) is important for screening high-yielding high-efficiency varieties and determining the rational allocation of water resources in winter wheat production. Compared with vertical observation angles, multi-angle remote sensing provides more information on mid to lower parts of the wheat canopy, thereby improving estimates of physical and chemical indicators of the entire canopy. In this study, multi-angle spectral reflectance and the WUE of the wheat canopy were obtained at different growth stages based on field experiments carried out across 4 years using three wheat varieties under different water and nitrogen fertilizer regimes. Using appropriate spectral parameters and sensitive observation angles, the quantitative relationships with wheat WUE were determined. The results revealed that backward observation angles were better than forward angles, while the common spectral parameters Lo and NDDAig were found to be closely related to WUE, although with increasing WUE, both parameters tended to become saturated. Using this data, we constructed a doubleratio vegetation index (NDDAig/FWBI), which we named the water efficiency index (WEI), reducing the impact of different test factors on the WUE monitoring model. As a result, we were able to create a unified monitoring model within an angle range of $-20-10^{\circ}$. The equation fitting determination coefficient $\left(R^{2}\right)$ and root mean square error (RMSE) of the model were 0.623 and 0.406 , respectively, while an independent experiment carried out to test the monitoring models confirmed that the model based on the new index was optimal, with $R^{2}$, RMSE, and relative error (RE) values of $0.685,0.473$, and $11.847 \%$, respectively. These findings suggest that the WEI is more sensitive to WUE changes than common spectral parameters, while also allowing wide-angle adaptation, which has important implications in parameter design and the configuration of satellite remote sensing and UAV sensors.

Keywords: winter wheat, hyperspectral remote sensing, angle adaptability, water use efficiency, monitoring model 


\section{INTRODUCTION}

Wheat is one of the important food crops in the world, and with recent economic development and population growth, the level of winter wheat production has become even more important for ensuring world food security. Meanwhile, due to global climate change, lack of water has become a key limiting factor in winter wheat production. Water use efficiency (WUE) is a broad agronomic concept that reflects the comprehensive effect of crops on water use. Leaf WUE is the main criterion used to measure drought tolerance and efficient water use in crops, and subsequent selection and screening of high WUE varieties is one of the most important goals of crop breeding (Richards, 2006; Zhang et al., 2007). Efficient use of limited water resources and increases in overall WUE has therefore become an urgent goal of winter wheat production.

Leaf WUE is defined as the ratio of net photosynthesis $\left(\mathrm{P}_{\mathrm{N}}\right)$ to transpiration (Tr; Condon et al., 2002), which can be estimated using the carbon isotope ratio $\left(\delta^{13} \mathrm{C}\right.$; Hultine and Marshall, 2000). Recently, rapid development of remote sensing technology has provided an effective tool for largescale analysis of water use in crops. Compared with traditional crop WUE monitoring and diagnostic tools, hyperspectral remote sensing technology has made it possible to obtain a huge amount of continuous large-scale data in a more efficient manner (Peñuelas et al., 1993b; Dong et al., 2011). Ground hyperspectral remote sensing technology selects sensitive bands using spectral characteristic information to obtain vegetation indexes, which are used to establish estimation models (Hatfield et al., 2008; Mistele and Schmidhalter, 2008).

An appropriate water content is the basis of vigorous plant growth and efficient water use. As early as 1971, Thomas et al. (1971) analyzed the relationship between the leaf water content (LWC) and spectral reflectance, and revealed a strong correlation with reflectance at 1450 and $1930 \mathrm{~nm}$. Similarly, Carter (1991) suggested that the nearinfrared absorption peak at $950-970 \mathrm{~nm}$ could be used to monitor plant moisture content, while Dawson et al. (1999) examined the performance of the moisture spectral index to estimate the canopy water content, revealing that indexes based on 970 and $1200 \mathrm{~nm}$ water absorption characteristics had a high coefficient of determination (Dawson et al., 1999). However, studies also suggest that reflectance at 970 , 1200 , and $1900 \mathrm{~nm}$ is easily affected by starch, protein, and nitrogen (Curran, 1989). For example, Sims and Gamon (2003) revealed that the best spectral bands for remote estimates of the plant water content at the canopy scale were 1150-1260 and 1520-1540 nm (Sims and Gamon, 2003), while in addition to the near infrared region, reflectance at 690 and $740 \mathrm{~nm}$ have also been shown to reflect water stress in plants (Dobrowski et al., 2005). Screening and analysis of spectral bands that are sensitive to water also provides a basis for the establishment of relevant vegetation indexes that reflect the water status. Peñuelas et al. (1993a) combined the water absorption band at $970 \mathrm{~nm}$ and the reference band at $900 \mathrm{~nm}$ as a ratio to establish a water index (WI) capable of tracking changes in water content. Similarly, Zarco-Tejada et al. (2003) used MODIS data to construct a plant water index (PWI) for monitoring vegetation moisture content, and revealed good consistency with the water content of ground crops (Zarco-Tejada et al., 2003). Moreover, the floating-position water band index (FWBI) has also been established, which uses the reflectance at $900 \mathrm{~nm}$ and minimum reflectance at $900-980 \mathrm{~nm}$ to represent the water status (Strachan et al., 2002). Yao et al. (2014) subsequently introduced a new water-sensitive band based on the normalized vegetation index $\operatorname{NDSI}(1429,416)$ to construct a three-band vegetation index capable of estimating the leaf equivalent water thickness. However, these previous studies mainly used the sensor to obtain two-dimensional information of the crop in a vertical direction, and failed to include data from middle to lower parts of the canopy. The accuracy of remote sensing monitoring therefore requires further improvements.

Compared with vertical observation angles, the multiangle observation method collects data from different directions, providing multi-dimensional information and representing a new method of remote sensing monitoring (Thenkabail et al., 2000; Pocewicz et al., 2007; Huang et al., 2011). A number of studies have been carried out to extract optical and structural information using multi-angle observations (Cierniewski et al., 2004; Rautiainen et al., 2004), suggesting that multi-angle remote sensing technology can improve the ability of a vegetation index to estimate crop canopy structure and distinguish between crop varieties (Shibayama and Wiegand, 1985; Diner et al., 1999). The photochemical reflectance index (PRI) is notably affected by the observation angle. For example, PRI values calculated using backward spectral data tend to be higher than those obtained with forward observation data (Drolet et al., 2008; Garbulsky et al., 2011; Middleton et al., 2011). Furthermore, Galvão et al. (2009) found that data collected in a backscattering direction was better at distinguishing between different soybean varieties, while Chopping et al. (2003) obtained canopy characteristics of desert grassland using multi-angle remote sensing data. Chen et al. (2005) and Leblanc et al. (2005) proposed a multi-angle index for measuring leaf aggregation based on hot and dark spot reflectivity. Multi-angle hyperspectral remote sensing has also made great progress in estimations of crop pigment content and nitrogen content (Stagakis et al., 2010; He et al., 2015). Meanwhile, He et al. (2016) constructed an angle insensitivity index (AIVI) based on analysis of different bands and vegetation indexes, improving the accuracy of plant nitrogen content estimations and expanding the scope of application.

In the field of remote sensing monitoring, in addition to analyses of vegetation canopy structure and physiological indicators, the performance indicators of crop production are also important. The $\mathrm{P}_{\mathrm{N}}$ of field crops has been shown to be significantly correlated with physiological indicators, and studies suggest the use of the ratio vegetation index $\left(\mathrm{R}_{810 / 680}\right)$ 
to directly estimate the $\mathrm{P}_{\mathrm{N}}$ of rice leaves (Tian et al., 2005). In addition, based on hyperspectral data, Zhang et al. (2018) established an estimation model of nitrogen fertilizer use efficiency in winter wheat, while photosynthetic effective radiation (FPAR) captured by the canopy can also be directly obtained through multi-angle remote sensing (Chen et al., 2003).

Light use efficiency (LUE) is one of the most important traits in crops, and is usually reflected by the PRI (ZarcoTejada et al., 2013). For example, Hall et al. (2008) proposed a method to obtain forest LUE directly from space by measuring the shadow component of the PRI based on multi-angle spectral information (Hall et al., 2008). Meanwhile, Bastiaanssen et al. (1999) used remote sensing data to estimate crop yield and crop transpiration (ETc), and then determined the WUE of crops in the Barkra region of India. Li et al. (2005) also used remote sensing observation means combined with meteorological data to invert crop WUE in the Haihe River Basin by estimating crop transpiration. Thus, while progress has been made in the use of remote sensing data to monitor crop WUE, the monitoring indicators, methods, and models remain inconsistent due to geographical differences and crop types, as well as differences in cultivation conditions. However, estimations of WUE utilization efficiency at the leaf scale based on hyperspectral remote sensing data are lacking, especially with regards the influence of different observation angles, and the angle range of model adaptation requires further clarification. The main goal of this study, therefore, was to create a model capable of estimating the instantaneous WUE of winter wheat leaves based on multi-angle hyperspectral remote sensing data. By clarifying the relationship between common spectral parameters and WUE at different vertical angles, a new vegetation index for estimating WUE was established. The new parameter was then compared with common vegetation indexes under different observation angles, and the optimal range of angles was determined, allowing establishment of a unified estimation equation. The findings provide a theoretical basis for realtime accurate monitoring of water use in winter wheat, supporting the screening of germplasm resources and efficient irrigation management.

\section{MATERIALS AND METHODS}

\section{Experimental Design}

Five experiments were carried out across 4 years at two different locations. Various water management, $\mathrm{N}$ rates, and cultivars of hexaploid winter wheat (Triticum aestivum L.) were studied, specific details are shown in Table 1. Experiments 1-4 were completed in the experimental station of Henan Agricultural University $\left(35^{\circ} 51^{\prime} \mathrm{N}, 113^{\circ} 35^{\prime} \mathrm{S}\right)$, Zhengzhou, Henan Province, China, in fluvo-aquic soil. Experiments 1 and 4 were completed in 2016-17, and experiments 2 and 3 in 2017-18 and 2018-19, respectively. Experiment 5 was completed at Shangshui experimental station in Zhoukou, Henan Province $\left(33^{\circ} 33^{\prime} \mathrm{N}\right.$, $\left.114^{\circ} 37^{\prime} \mathrm{S}\right)$, in $2017-18$, in lime concretion black soil. The experiments 1,4 , and 5 consisted of a only one irrigation regiments (twice irrigation, $750 \mathrm{~m}^{3} \mathrm{ha}^{-1}$ at jointing plus anthesis stage), experiments $2-3$ consisted of a three irrigation regiments (no irrigation, single irrigation of $750 \mathrm{~m}^{3} \mathrm{ha}^{-1}$, and irrigation750 $\mathrm{m}^{3} \mathrm{ha}^{-1}$ at jointing plus anthesis stage). Three different winter wheat cultivars were examined, two erect (Yumai 49-198 and Zhoumai 27) and one horizontal (Zhengmai 9694).

TABLE 1 | Seasons, soil status, cultivars, nitrogen rates, irrigation frequency, and sampling dates for five experiments.

\begin{tabular}{|c|c|c|c|c|}
\hline Exp. no. & $\begin{array}{l}\text { Season, Site, } \\
\text { and Cultivar }\end{array}$ & Soil characteristics & Treatments & Sampling stage \\
\hline Exp. 1 & $\begin{array}{l}\text { 2016-2017 } \\
\text { Zhengzhou } \\
\text { Yumai49-198 }\end{array}$ & 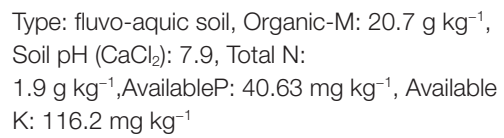 & $\begin{array}{l}\text { Irrigated } \mathrm{N}: \mathrm{N} \text { rate }\left(\mathrm{kg} \mathrm{ha}^{-1}\right), \mathrm{W}_{2}:\left[\mathrm{N}_{0}(0), \mathrm{N}_{6}(60), \mathrm{N}_{12}(120), \mathrm{N}_{18}(180)\right. \\
\left.\mathrm{N}_{24}(240)\right] . \mathrm{N}: 50 \% \text { prior to seeding and } 50 \% \text { at jointing. Irrigation } \\
\text { frequencies: } \mathrm{W}_{2} \text { (twice at jointing and anthesis stage). }\end{array}$ & $\begin{array}{l}\text { Booting } \\
\text { Anthesis }\end{array}$ \\
\hline Exp. 2 & $\begin{array}{l}\text { 2017-2018 } \\
\text { Zhengzhou } \\
\text { Yumai49-198 }\end{array}$ & $\begin{array}{l}\text { Type: fluvo-aquic soil, Organic-M: } 16.8 \mathrm{~kg}^{-1} \text {, } \\
\text { Soil } \mathrm{pH}\left(\mathrm{CaCl}_{2}\right): 7.8 \text {, Total } \mathrm{N}: 0.92 \mathrm{~g} \mathrm{~kg}^{-1} \text {, } \\
\text { Available P: } 18.90 \mathrm{mg} \mathrm{kg}^{-1} \text {, Available K: } \\
152.64 \mathrm{mg} \mathrm{kg}^{-1}\end{array}$ & $\begin{array}{l}\text { Water and nitrogen coupling: } N \text { rate }(k g \text { ha-1 }), W_{0}:\left[N_{0}(0), N_{6}(60) \text {, }\right. \\
\left.N_{12}(120), N_{18}(180), N_{24}(240)\right], W_{1}:\left[N_{0}(0), N_{6}(60), N_{12}(120), N_{18}(180) \text {, }\right. \\
\left.N_{24}(240)\right], W_{2}:\left[N_{0}(0), N_{6}(60), N_{12}(120), N_{18}(180), N_{24}(240)\right] \text {. Irrigation } \\
\text { frequencies: } W_{0}(n o n e), W_{1}\left(\text { once at jointing stage), } W_{2} \text { (twice at }\right. \\
\text { jointing and anthesis stage). }\end{array}$ & $\begin{array}{l}\text { Booting } \\
\text { Heading } \\
\text { Anthesis }\end{array}$ \\
\hline Exp. 3 & $\begin{array}{l}\text { 2018-2019 } \\
\text { Zhengzhou } \\
\text { Yumai49-198 }\end{array}$ & $\begin{array}{l}\text { Type: fluvo-aquic soil, Organic-M: } 16.8 \mathrm{~kg}^{-1} \text {, } \\
\text { Soil } \mathrm{pH}\left(\mathrm{CaCl}_{2}\right): 7.8 \text {, Total } \mathrm{N}: 0.92 \mathrm{~g} \mathrm{~kg}^{-1} \text {, } \\
\text { Available P: } 18.90 \mathrm{mg} \mathrm{kg}^{-1} \text {, Available K: } \\
152.64 \mathrm{mg} \mathrm{kg}^{-1}\end{array}$ & $\begin{array}{l}\text { Water and nitrogen coupling: } N \text { rate }(\mathrm{kg} \mathrm{ha}-1), W_{0}:\left[N_{0}(0), N_{6}(60) \text {, }\right. \\
\left.N_{12}(120), N_{18}(180), N_{24}(240)\right], W_{1}:\left[N_{0}(0), N_{6}(60), N_{12}(120), N_{18}(180) \text {, }\right. \\
\left.N_{24}(240)\right], W_{2}:\left[N_{0}(0), N_{6}(60), N_{12}(120), N_{18}(180), N_{24}(240)\right] \text {. Irrigation } \\
\text { frequencies: } W_{0}\left(\text { none), } W_{1}\left(\text { once at jointing stage), } W_{2} \text { (twice at }\right.\right. \\
\text { jointing and anthesis stage). }\end{array}$ & $\begin{array}{l}\text { Booting } \\
\text { Heading } \\
\text { Anthesis }\end{array}$ \\
\hline \multirow[t]{3}{*}{ Exp. 5} & $\begin{array}{l}\text { 2017-2018 } \\
\text { Shangshui }\end{array}$ & $\begin{array}{l}\text { Type: lime concretion black soil, Organic-M: } \\
\mathrm{kg}^{-1} \text {, Soil } \mathrm{pH}\end{array}$ & \multirow{3}{*}{$\begin{array}{l}\text { Irrigated N: N rate (kg ha-1), } W_{2}:\left[N_{0}(0), N_{6}(60), N_{12}(120), N_{18}(180) \text {, }\right. \\
\left.N_{24}(240)\right] . N: 50 \% \text { prior to seeding and } 50 \% \text { at jointing. Irrigation } \\
\text { frequencies: } W_{2} \text { (twice at jointing and anthesis stage). }\end{array}$} & Heading \\
\hline & Zhoumai27 & $\begin{array}{l}\text { (CaCl2): 7.0, Total } \mathrm{N}: \mathrm{kg}^{-1} \text {, Available } \mathrm{P}: \\
4.87 \mathrm{mg} \mathrm{kg}^{-1} \text {, }\end{array}$ & & Anthesis \\
\hline & & Available K: $176.52 \mathrm{mg} \mathrm{kg}^{-1}$ & & \\
\hline
\end{tabular}


Experimental plots 1-4 covered an area of $7 \times 2.9 \mathrm{~m}$, respectively, planted in a north-south direction, with $18 \mathrm{~cm}$ row spacing, while plot 5 covered an area of $9 \times 6 \mathrm{~m}$, planted in a northsouth direction, with $20 \mathrm{~cm}$ row spacing. All experiments followed a completely randomized block design, and each treatment was repeated three times. All plots were managed according to local standard management practices.

\section{Measurements of Agronomic Indicators}

The $\mathrm{P}_{\mathrm{N}}$ and $\mathrm{Tr}$ of the top leaf were determined in the field using a photosynthetic device (LI-6400 photosynthetic rate system; Li-Cor Inc., United States). Measurements were obtained in the open at a carbon dioxide concentration of approximately $385 \mu \mathrm{mol} 1^{-1}$. The built-in light source was set at $1600 \mu \mathrm{mol} \mathrm{m} \mathrm{m}^{-2} \mathrm{~s}^{-1}$. The ratio of $\mathrm{P}_{\mathrm{N}}$ and $\operatorname{Tr}$ was then used to reflect the WUE. Measurements were taken at the booting, heading, anthesis, initial-filling, and mid-filling stages.

Twenty representative plants from each treatment were then randomly selected and brought back to the laboratory where they were separated into stem and leaf samples. Leaf weight (FW) was recorded before drying the samples in an oven at $105^{\circ} \mathrm{C}$ for $30 \mathrm{~min}$ then to a constant weight at $70^{\circ} \mathrm{C}$. The dry mass of the leaves (DW) was then determined and the LWC was calculated as follows:

\section{$\mathrm{LWC}=(\mathrm{FW}-\mathrm{DW}) / \mathrm{FW}$.}

Plant leaf samples were simultaneously dried to a constant weight then crushed and passed through a sieve before determining the leaf nitrogen content (LNC) using the Kjeldahl method.

\section{Canopy Spectrum Acquisition}

At the same time as measuring the WUE, the spectral reflectance of the winter wheat canopy was also determined. A FieldSpec Pro FR 2500 back-mounted field hyperspectral radiometer (Analytical Spectral Device, American ASD Company) was used to sample 10 points per $1 \mathrm{~m}^{2}$, which were then averaged as one point of data. Measurements were made on a sunny day with no cloud cover between 10:00 and 12:00 a.m. The field of view of the spectrometer was set at $25^{\circ}$, the spectral range was $350-1075 \mathrm{~nm}$, and the sampling interval was $1.6 \mathrm{~nm}$. Before sampling and during use, a $40 \times 40 \mathrm{~cm} \mathrm{BaSO}_{4}$ whiteboard was used for calibration. To obtain multi-angle spectrum, a probe was fixed to the multi-angle observation frame according to the design of the field angle measurement system (FIGOS, Figure 1). A total of 13 observation angles were examined following the principal plane of the sun, with the sunny side representing backward observation angles $(-60,-50,-40,-30$, -20 , and $-10^{\circ}$, respectively), and angles on the opposite side representing forward observation angles $(10,20,30,40,50$, and $60^{\circ}$, respectively), with the vertical angle set at $0^{\circ}$.

\section{Data Application}

A self-developed computation program was used to optimize the sensitive band combinations and equations using MATLAB 7.0 software. Data from experiments 1-3 were used to construct the new vegetation index and WUE estimation model, while independent data from experiments 4-5 were used to test the model by comparing differences between the coefficient of determination $\left(R^{2}\right)$, root mean square error (RMSE), and relative error (RE, \%). A 1:1 scatter plot was then used to show the effect of the model. Some common spectral indices were calculated using the equation listed in Table 2. RMSE and RE were calculated as follows:

$$
\begin{aligned}
& \mathrm{RMSE}=\sqrt{\frac{1}{\mathrm{n}} \times \sum_{\mathrm{i}=1}^{\mathrm{n}}\left(\mathrm{P}_{\mathrm{i}}-\mathrm{Q}_{\mathrm{i}}\right)^{2}}(1) \\
& \mathrm{RE}=\sqrt{\frac{1}{\mathrm{n}} \times \sum_{\mathrm{i}=1}^{\mathrm{n}}\left(\frac{\mathrm{P}_{\mathrm{i}}-\mathrm{Q}_{\mathrm{i}}}{\mathrm{Q}_{\mathrm{i}}}\right)^{2}} \times 100(2)
\end{aligned}
$$

where $P_{i}$ and $Q_{i}$ represent the predicted and measured values, respectively, and $\mathrm{n}$ represents the number of samples.

\section{RESULTS}

\section{Quantitative Relationships Between the Leaf Nitrogen Content, Water Content, and WUE}

Based on the data from experiments 1-3, the relationships between the LNC, LWC, and ratio between LNC/LWC under different experimental conditions was analyzed in terms of the WUE (Figure 2). As shown in Figure 2A, when the irrigation treatment conditions are not distinguished, the relationship between LNC and WUE was generally poor $\left(R^{2}=0.366\right)$. Under a single water treatment condition, the LNC showed a significant linear relationship with the WUE, and the correlation was best under $\mathrm{W}_{1}$ (once water at jointing stage) conditions $\left(R^{2}=0.869\right)$, followed by $\mathrm{W}_{0}$ conditions $\left(R^{2}=0.803\right)$. The worst correlation was observed under $\mathrm{W}_{2}$ (twice water at jointing and anthesis stage) conditions $\left(R^{2}=0.682\right)$. Similarly, the relationship between

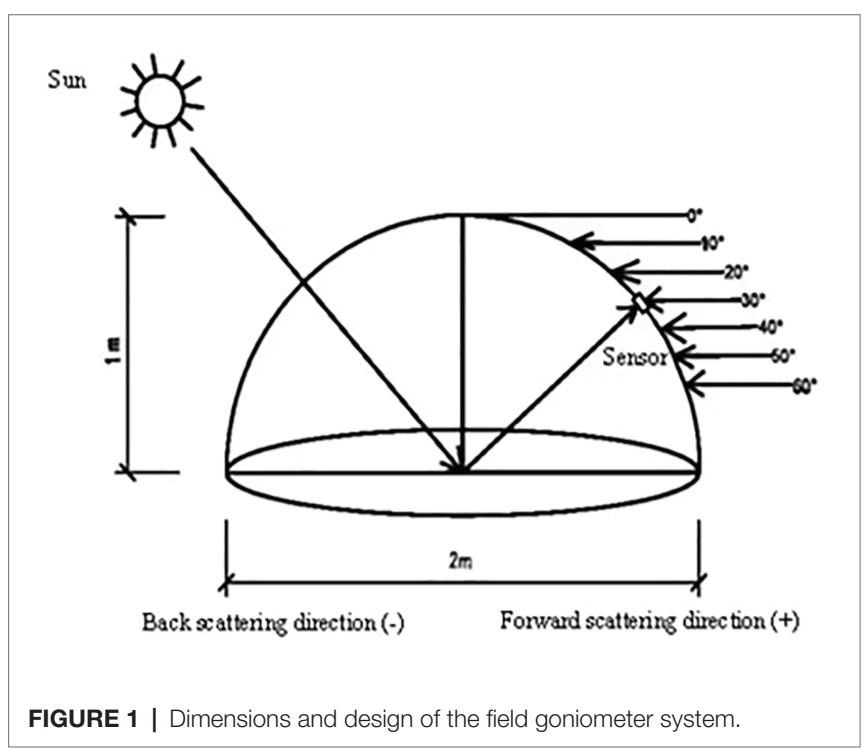



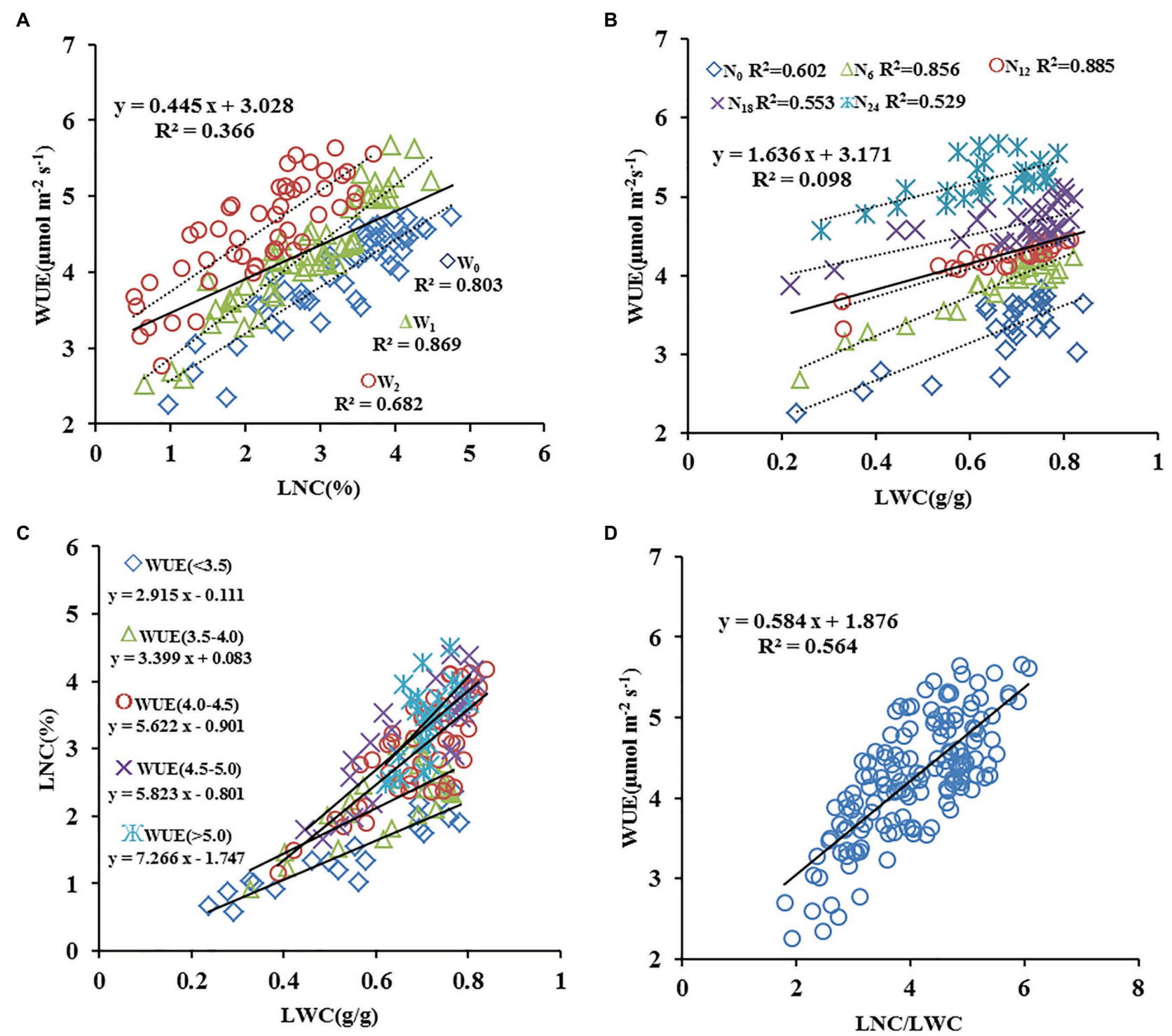

FIGURE 2 | Quantitative relationships between leaf nitrogen (N) content (LNC: A), water content (LWC: B), LNC/LWC (D) and water use efficiency (C: The relation between LWC and LNC. WUE; $n=140$ ).

the LWC and WUE was also affected by nitrogen treatment. Overall, the $R^{2}$ between the LWC and WUE was only 0.098 (Figure 2B). Under different nitrogen treatment conditions, the relationship between LWC content and WUE was significant. The transition from high to low nitrogen treatment caused an increase followed by a decrease in $R^{2}$, with $\mathrm{N}_{12}\left(120 \mathrm{~kg} \mathrm{ha}^{-1}\right)$ treatment giving the highest value $\left(R^{2}=0.885\right)$. The relationships between the LNC and LWC content and WUE were therefore affected by each other, and these relationships were therefore analyzed further. Results revealed that the variation in WUE was closely related to the slope between LNC and LWC. With increasing WUE, the slope of the equation between LNC and LWC gradually increased (Figure 2C), and there was a significant positive correlation between the LNC/LWC ratio and WUE
$\left(R^{2}=0.564\right.$, Figure 2D). These findings suggest that the LNC/ LWC ratio more accurately reflects the dynamic changes in WUE under different water and nitrogen conditions.

\section{Relationship Between Common Spectral Parameters and WUE at the Vertical Observation Angle}

The relationships between 330 previously reported vegetation indices and WUE were subsequently analyzed, then the best 12 were selected (Figure 3). As shown in the figure, the $R^{2}$ between WUE and only three of these parameters was greater than 0.4 ( $R^{2}$ of Lo, EVI-1 and NDDAig: 0.439, 0.523, and 0.545 ; RMSE: $0.539,0.511$, and 0.500 , respectively). To further 
TABLE 2 | Summary of selected spectral parameters reported in the literature.

\begin{tabular}{|c|c|c|}
\hline $\begin{array}{l}\text { Vegetation } \\
\text { indices }\end{array}$ & Formula & Reference \\
\hline $\operatorname{DVI}(810,680)$ & $\mathrm{R}_{810}-\mathrm{R}_{680}$ & Jordan, 1969 \\
\hline $\begin{array}{l}\text { SRPI } \\
\text { WBI-1 } \\
\text { WI } \\
\text { Readone } \\
\text { Lo } \\
\text { PSRI } \\
\mathrm{R}_{433} /\left(\mathrm{R}_{496}+\mathrm{R}_{401}\right) \\
\mathrm{R}_{705} /\left(\mathrm{R}_{717}+\mathrm{R}_{491}\right) \\
\mathrm{FWBI} \\
\mathrm{PRI}(570,531)\end{array}$ & $\begin{array}{l}\mathrm{R}_{430} / \mathrm{R}_{680} \\
\mathrm{R}_{950} / \mathrm{R}_{900} \\
\mathrm{R}_{900} / \mathrm{R}_{970} \\
\mathrm{R}_{415} / \mathrm{R}_{695} \\
\min \left(\mathrm{R}_{680-780}\right) \\
\left(\mathrm{R}_{680}-\mathrm{R}_{500}\right) / \mathrm{R}_{750} \\
\mathrm{R}_{434} /\left(\mathrm{R}_{496}+\mathrm{R}_{401}\right) \\
\mathrm{R}_{705} /\left(\mathrm{R}_{717}+\mathrm{R}_{491}\right) \\
\mathrm{R}_{900} / \mathrm{min}\left(\mathrm{R}_{930-980}\right) \\
\left(\mathrm{R}_{531}-\mathrm{R}_{570}\right) /\left(\mathrm{R}_{531}+\mathrm{R}_{570}\right)\end{array}$ & $\begin{array}{l}\text { Peñuelas et al., 1995a } \\
\text { Peñuelas et al., } 1993 a \\
\text { Peñuelas et al., } 1997 \\
\text { Read et al., } 2002 \\
\text { Miller et al., } 1990 \\
\text { Merzlyak et al., } 1999 \\
\text { Tian et al., } 2011 \\
\text { Tian et al., } 2011 \\
\text { Strachan et al., } 2002 \\
\text { Gamon et al., } 1992\end{array}$ \\
\hline $\operatorname{SIPI}(800,680,445)$ & $\left(\mathrm{R}_{800}-\mathrm{R}_{445}\right) /\left(\mathrm{R}_{800}-\mathrm{R}_{680}\right)$ & $\begin{array}{l}\text { Peñuelas et al., } 1995 a \\
\text { Sims and Gamon, }\end{array}$ \\
\hline mSR705 & $\left(\mathrm{R}_{750}-\mathrm{R}_{445}\right) /\left(\mathrm{R}_{705}-\mathrm{R}_{445}\right)$ & 2002 \\
\hline RES & $\left(\mathrm{R}_{718}-\mathrm{R}_{675}\right) /\left(\mathrm{R}_{755}-\mathrm{R}_{675}\right)$ & $\begin{array}{l}\text { Ju et al., } 2010 \\
\text { Santos and Negri, }\end{array}$ \\
\hline NDVI $(895,675)$ & $\left(\mathrm{R}_{895}-\mathrm{R}_{675}\right) /\left(\mathrm{R}_{895}+\mathrm{R}_{675}\right)$ & 1997 \\
\hline NDRE & $\left(\mathrm{R}_{790}-\mathrm{R}_{720}\right) /\left(\mathrm{R}_{790}+\mathrm{R}_{720}\right)$ & Fitzgerald et al., 2006 \\
\hline $\operatorname{NRI}(570,670)$ & $\left(R_{570}-R_{670}\right) /\left(R_{570}+R_{670}\right)$ & $\begin{array}{l}\text { Li et al., } 2005 \\
\text { Roujean and Breon, }\end{array}$ \\
\hline $\operatorname{RDVI}(800,670)$ & $\left(\mathrm{R}_{800}-\mathrm{R}_{670}\right) / \mathrm{sqrt}\left(\mathrm{R}_{800}+\mathrm{R}_{670}\right)$ & 1995 \\
\hline NDDAig & $\begin{array}{l}\left(\mathrm{R}_{755}+\mathrm{R}_{680}-2 \times \mathrm{R}_{705}\right) /\left(\mathrm{R}_{755}-\mathrm{R}_{680}\right) \\
{\left[\mathrm{R}\left({ }_{520-560}\right)-\mathrm{R}\left(\mathrm{R}_{630-600}\right)\right] /\left[\mathrm{R}\left(\mathrm{R}_{520-560}\right)+\right.}\end{array}$ & Feng et al., 2014 \\
\hline NDGI & $\begin{array}{l}\left.\mathrm{R}\left({ }_{630-690}\right)\right] \\
2.5^{\star}\left(\mathrm{R}_{860}-\mathrm{R}_{645}\right) /\left(1+\mathrm{R}_{860}+6^{\star} \mathrm{R}_{645^{-}}\right.\end{array}$ & Rouse et al., 1974 \\
\hline $\begin{array}{l}\text { EVI-1 } \\
\text { MCARI }(700,670,\end{array}$ & $\left.7.5^{*} \mathrm{R}_{470}\right)$ & Huete et al., 2002 \\
\hline 550) & $\begin{array}{l}{\left[\left(R_{700}-R_{670}\right)-0.2^{*}\left(R_{700}-R_{550}\right)\right]^{*}\left(R_{700} / R_{670}\right)} \\
\left(R_{520-560}-R_{630-690}\right) /\left(R_{520-560}+R_{630}\right.\end{array}$ & Daughtry et al., 2000 \\
\hline Vari-GREEN & $\begin{array}{l}\left.{ }_{690}-\mathrm{R}_{430-470}\right) \\
1.4735^{\star}\left(\mathrm{R}_{780}+1.4735^{\star} \mathrm{R}_{650^{-}}\right.\end{array}$ & Gitelson et al., 2002 \\
\hline TSAVI(800, 670) & $\begin{array}{l}\left(-1.4735^{\star} R_{780}+R_{650}+1.4735^{\star} 1.3681\right) \\
{\left[\left(R_{755}+R_{680}-2^{*} R_{705}\right)^{*} \operatorname{Min}\left(R_{930-980}\right)\right] /}\end{array}$ & $\begin{array}{l}\text { Baret and Guyot, } \\
1991\end{array}$ \\
\hline WEI & {$\left[\left(\mathrm{R}_{755}-\mathrm{R}_{680}\right)^{*} \mathrm{R}_{900}\right]$} & This study \\
\hline
\end{tabular}

improve the estimation accuracy using the relationship between LNC/LWC and WUE, LNC and LWC were converted using related vegetation indexes then the relationship with WUE was analyzed further. Ten indexes representing the LNC and seven representing the LWC were combined to create different ratios of the two vegetation indexes then the correlations with WUE were determined at a vertical angle (Figure 4). Ten combinations showed a $R^{2}$ greater than 0.40 , and of these, three had an $R^{2}$ exceeding 0.50 and were considered optimal (NDDAig/FWBI, NDDAig/WBI-1, and SPRI/WBI-1). Overall, the combination of NDDAig/FWBI performed the best $\left(R^{2}=0.624\right)$.

The quantitative relationships between the two common spectral parameters Lo and NDDAig and the optimized novel ratio vegetation index (NDDAig/FWBI) and WUE are shown as a scatter plot in Figure 5. A significant linear correlation was revealed between Lo and WUE $\left(R^{2}=0.523\right.$ and RMSE $=0.501$, Figure 5A), with an obvious saturation phenomenon. Compared with Lo, the NDDAig model showed improvement $\left(R^{2}=0.543\right.$, RMSE $=0.486$, Figure 5B $)$, although the combined NDDAig/FWBI index gave the best results $\left(R^{2}=0.624,19.31\right.$ and $14.92 \%$ higher than that of Lo and NDDAig, respectively; RMSE $=0.441,13.61$, and $10.20 \%$ lower than that of Lo and NDDAig, respectively), with obvious weakening of the saturation phenomenon. Based on highest $R^{2}$ values, the new ratio vegetation index (NDDAig/FWBI) was constructed to generate a water efficiency index (WEI).

\section{Relationships Between the Spectral Parameters and WUE at Different Zenith Angles}

Based on the data from experiments1-3, the relationships between the 12 common vegetation indexes and new combined index WEI were analyzed in terms of WUE under different observation angles (Table 3). Overall, except for angles of -60 and $-50^{\circ}$, all spectral parameters had a higher backward $R^{2}$ than forward $R^{2}$, especially in the range of $-40-30^{\circ}$. Moreover, the optimal observation angles of the different vegetation indexes were inconsistent with the monitoring accuracy. Two of the 13 spectral parameters (GVI and $\mathrm{TC}_{2}$ ) had an optimal observation angle of $0^{\circ}$ with $R^{2}$ values of 0.375 and 0.365 , respectively, while five spectral parameters [TSAVI $(800,670)$, RDVI (800, 670), PSRI, SIPI $(800,680,445)$, and EVI-1] had an optimal angle of $-20^{\circ}$ with $R^{2}$ values of $0.424,0.406,0.407,0.422$, and 0.472 , respectively. It is worth noting that the optimal observation angle of seven of the indexes was $-10^{\circ}$, suggesting that observation angles of -10 to $-20^{\circ}$ are important when monitoring the WUE of winter wheat leaves.

Compared with the common spectral parameters, the new vegetation index WEI showed obvious advantages at specific observation angles, especially an angle of $-10^{\circ}$. The $R^{2}$ and RMSE of the WEI model at different zenith angles are shown in Figure 6. The $R^{2}$ was highest in an angle range of $-20-10^{\circ}$ and the RMSE was relatively low.

\section{Relationship Between the New Spectral Parameter and WUE Under Different Angle Ranges}

From a single observation angle point of view, the monitoring accuracy of the new combined index was highest within a range of $-20-10^{\circ}$, with highest precision at $-10^{\circ}\left(R^{2}\right.$ and RMSE: 0.635 and 0.441, respectively). By combining the data from different observation angles, equation fitting was further analyzed under five observation angle ranges according to the principle of adjacent observation angles. As shown in Figure 7, the monitoring accuracy of WEI was higher than that of Lo and NDDAig, and the RMSE value was lowest under different angle ranges. Compared with an observation angle of $-10^{\circ}$, the $R^{2}$ of WEI decreased by $6.72 \%$ within a range of $-20-20^{\circ}$, while the RMSE increased by $7.76 \%$ (Figure 8A). Meanwhile, the $R^{2}$ decreased by only $1.93 \%$ in a range of $-20-10^{\circ}$ and the RMSE increased by only $4.71 \%$ (Figure $8 B$ ). These findings suggest that within an angle range of $-20-10^{\circ}$, the WEI model reduces the dependency on the observation angle, increasing the applicability and stability of the model.

\section{Testing of the Estimation Model}

The WUE estimation models were subsequently tested with the independent test data obtained in experiments 4-5 using 


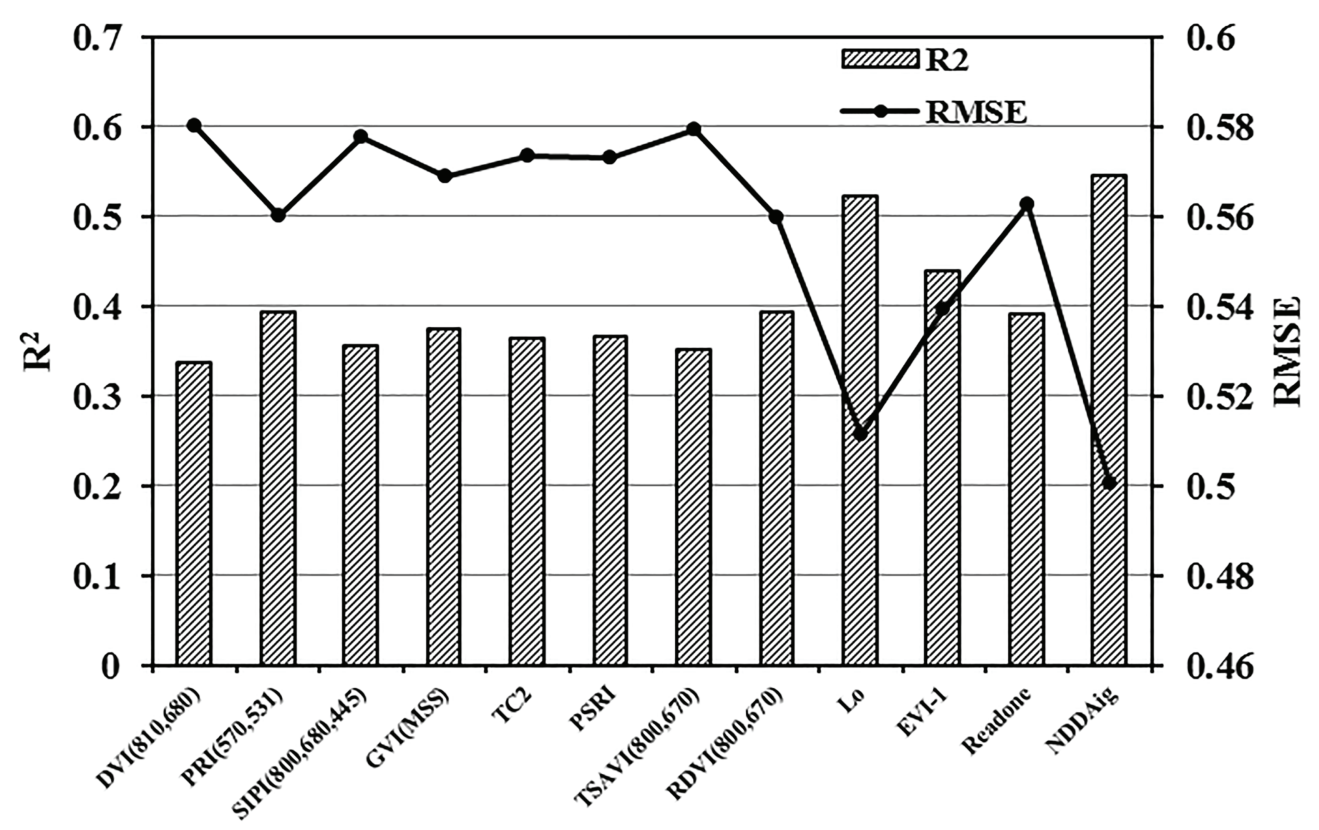

FIGURE 3 | Relationships between common vegetation indices and WUE $(n=140)$.

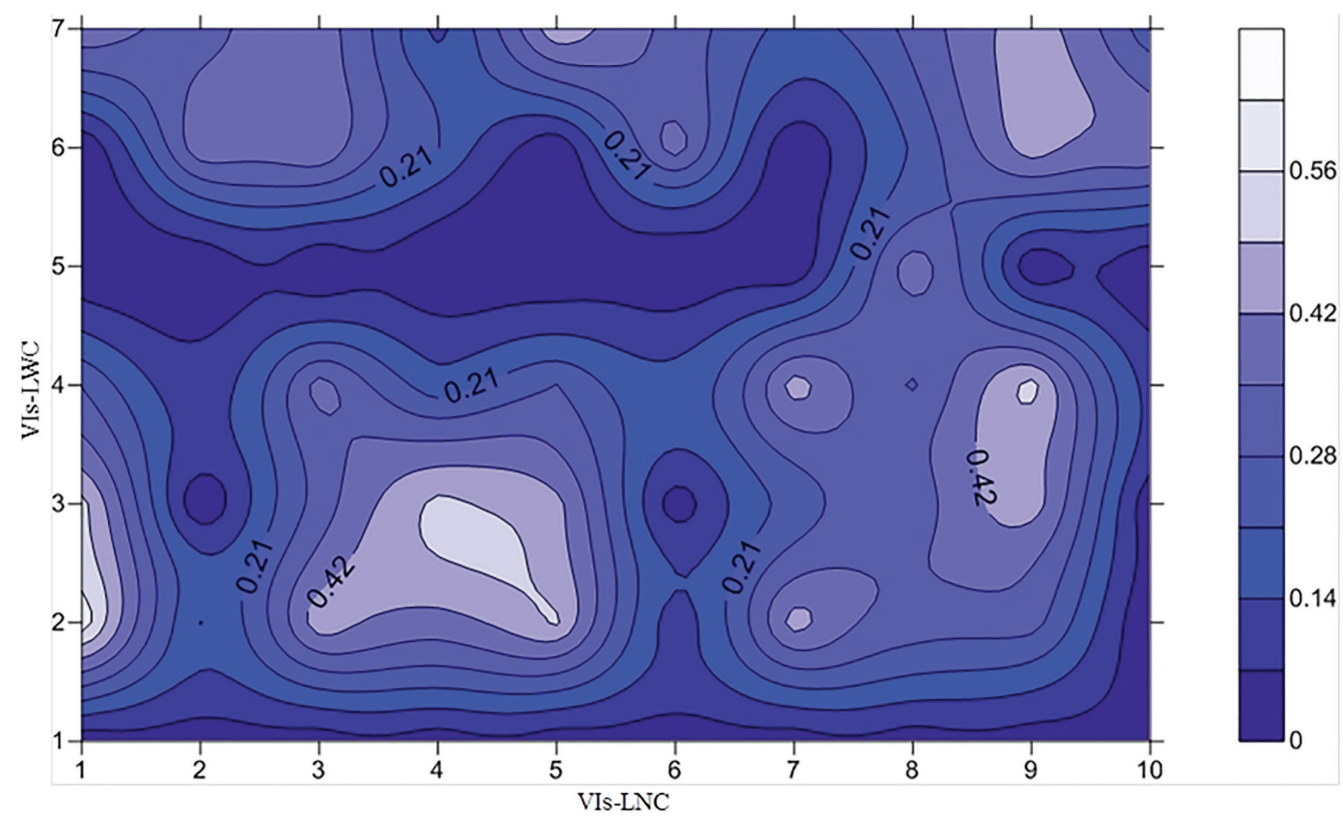

FIGURE 4 | Correlations between different parameter ratios and the WUE. [X-axis: VIs-LNC (vegetation indices related to LNC) 1-10 represent NDDAigig, R ${ }_{434}$ ] $\left(R_{496}+R_{401}\right), R_{705} /\left(R_{717}+R_{491}\right), S R P I, N D R E$, Lo, NRI, NDGl, RES, MCART (700, 670, and 550), respectively; Y-axis: Vls-LWC (vegetation indices related to LNC) 1-7 represent PRI (570 and 531), FWBI, WBI-1, WI, Vari-GREEN, mSR705, NDVI (895 and 675), respectively; $n=140$ ].

three indicators $\left(R^{2}, \mathrm{RMSE}\right.$, and RE). The prediction ability is shown as the ratio between predicted and observed values in Figure 9. The WUE model using NDDAig $\left(R^{2}=0.602\right.$,
RMSE $=0.474$, and $\mathrm{RE}=14.191 \%)$ as a variable was better than that using Lo $(0.517,0.523$, and $18.012 \%$, respectively); however, new parameter WEI gave better predictions, with 

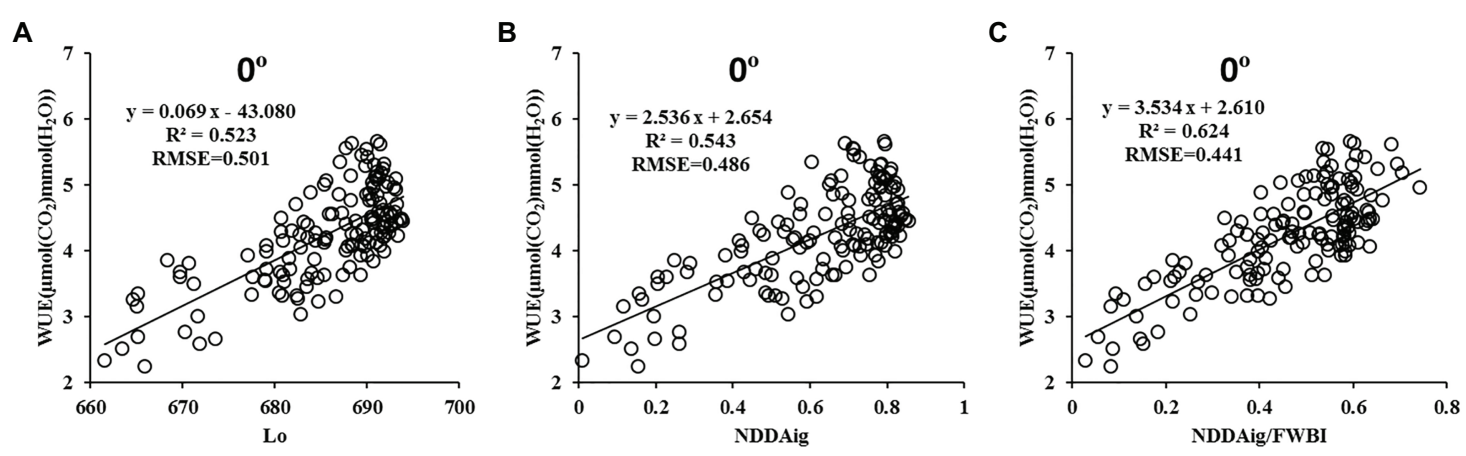

FIGURE 5 | Relationships between Lo (A), NDDAig (B), NDDAig/FWBI (C), and the WUE at a $0^{\circ}$ zenith angle $(n=140)$.

$R^{2}=0.685$, $\mathrm{RMSE}=0.403$, and $\mathrm{RE}=11.147 \%$. Overall, these findings suggest that the new combined index of WEI can be used to accurately monitor the WUE of winter wheat leaves.

\section{DISCUSSION}

Water and nutrients are not only the main stress factors affecting agricultural production, but they also interact with each other, playing individual as well as complimentary roles. The main aim of agricultural management, therefore, is to maximize the coupling effect of water and nitrogen, adjust water management according to nitrogen absorption, and use water management to promote nitrogen absorption (Sheshbahreh et al., 2019). Water stress significantly affects nitrogen absorption, while improved soil water conditions benefit nitrogen absorption and utilization. Increased uptake of nutrients under drought stress can also help improve drought resistance, while optimal increases in nitrogen fertilizer application can improve WUE and increase yield (Wolfe et al., 1988). As a result of the synergetic relationship between soil water and nitrogen, the changes in crop nitrogen and water contents are also synchronized. However, this relationship is also affected by irrigation and nitrogen fertilizer treatment. Meanwhile, this study confirmed that the relationship between the LNC and WUE is also affected by irrigation treatment, while at the same time, the relationship between the LWC and WUE is also affected by nitrogen fertilizer treatment. Thus, the use of LNC and LWC alone was relatively unreliable in characterizing the WUE. In contrast, the relationship between the ratio of LNC/LWC in terms of WUE was relatively less affected by irrigation and nitrogen fertilizer treatment. The coefficient of determination of the fitting equation was 0.564 , suggesting that the LNC/LWC ratio is a good indicator of dynamic changes in WUE. Overall, the findings confirmed that an increase in nitrogen in line with an increase in the water content of crop leaves is beneficial to overall water absorption.

The WUE of a plant is genetically controlled as well as being affected by the environment, and can therefore be improved by both breeding and cultivation measures.
A high WUE is beneficial in maintaining a certain yield under water stress, and therefore has important application value. In addition, WUE plays a significant role in estimations of net primary productivity $(\mathrm{NPP}=\mathrm{WUE} \times \mathrm{Tr})$ on a regional scale. However, recent studies have shown that the WUE is not constant, but rather it varies greatly with environmental conditions and the plant type (Yu et al., 2001). The use of remote sensing to rapidly and non-destructively determine the real-time WUE of a crop therefore provides important information for terrestrial ecosystem and water cycle models at different scales. The crop canopy spectrum provides mixed information, and is susceptible to factors such as plant coverage, soil type, and leaf area. Accordingly, a number of studies have aimed to construct new indexes that reduce noise and improve the estimation accuracy (Wang et al., 2012). For example, Peñuelas et al. (1997) and Pinol et al. (1998) successfully determined the humidity of combustibles using spectral data obtained in the field in the Mediterranean using a combined ratio spectral index (Peñuelas et al., 1997; Pinol et al., 1998). Studies have also shown that double-ratio vegetation indexes can reduce the effects of variables such as background and leaf area index (LAI), and provide more useful information for estimations of the vegetation canopy water content (Daughtry et al., 2000; Haboudane et al., 2002). Meanwhile, double-ratio vegetation indexes also include more sensitive bands, thus improving the estimation accuracy (Gitelson et al., 2017). Based on these studies, we therefore combined the close relationship between LNC/LWC and WUE to obtain a new spectral parameter, one indicate the change in nitrogen content of the leaf is selected, another parameter that is sensitive to the change in LWC is selected, the combination of these two vegetation indexes in the form of ratio provides an opportunity to invert WUE of leaves. To this end, we selected two spectral parameters of nitrogen content (NDDAig) and water content (FWBI), and combined the two (NDDAig/FWBI) to give a new index, WEI. Accordingly, estimations of the WUE of winter wheat leaves were greatly improved. Compared with common spectral parameters, the new WEI performed best at 13 angles, with optimal angle compatibility within the range of $-20-10^{\circ}$ $\left(R^{2}=0.623\right)$. The use of independent test data also confirmed the accuracy of the model. 

잉요

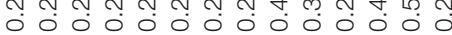

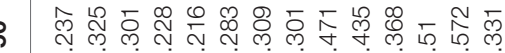
00000000000000

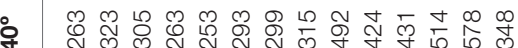

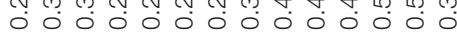

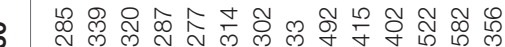

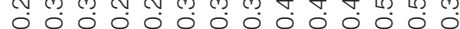

:

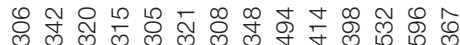

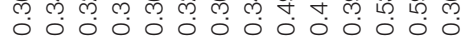

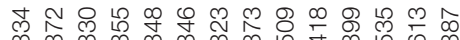

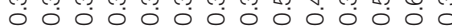

$\therefore$

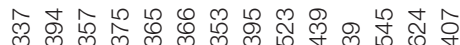

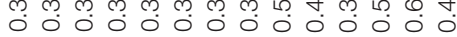

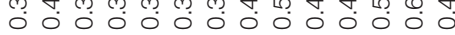

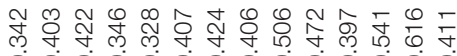

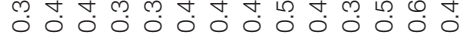

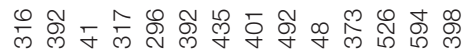

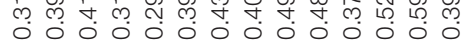

(1)

\&

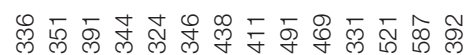

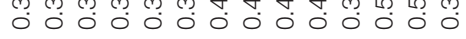

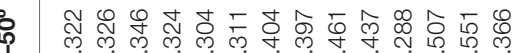

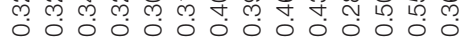

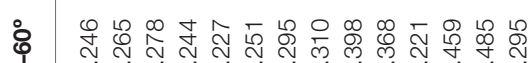

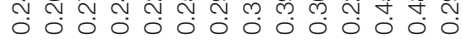

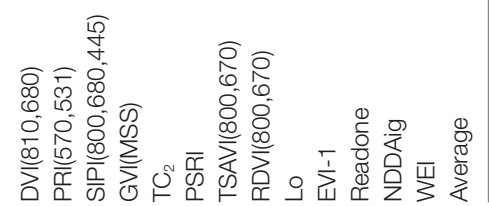

The difference between a vegetation index in different observation directions depends on various factors, including the crop canopy structure, the shape, and angle of the sensor, shadows, and the soil type (Kimes et al., 1985). In this study, the relationship between WEI and WUE also varied depending on the angle of observation. Pocewicz et al. (2007) made full use of the hotspot effect of the backward observation angles to improve the estimation accuracy of LAI (Pocewicz et al., 2007). Meanwhile, a multi-angle observation method was used to collect image data of the soybean canopy at different growth stages in the field, revealing that a $40^{\circ}$ zenith angle was the best angle for inverting chlorophyll density (Zhang et al., 2013). In this study, the $R^{2}$ between the spectral parameters and WUE decreased with increasing observation angle, possibly because a smaller angle results in more comprehensive information of the upper, middle, and lower canopies of the entire crop. The absorption of water by crop leaves is the result of interactions throughout the canopy; therefore, small-angle spectral information is important in determining an accurate WUE. In addition, the effects of backward observation angles were found to be better than those of forward observations. This is thought to be because when data is collected in a backward direction, the sensor is located on the same side as the sun, and data is mainly collected from canopy falling within the light. In contrast, the crop canopy with a larger shadow share is collected in a forward direction, although angles of $-60^{\circ}$ and $-50^{\circ}$ behave abnormally, possibly due to the decline in data quality at larger angles (Barnes and $\mathrm{Hu}, 2016$ ).

Compared with the vertical angle, the wider angle range not only resulted in more information on the crop canopy, but also expanded the application range of the sensor, increasing overall efficiency. In addition to determining the best observation angle, it is also important to comprehensively model data from different angles to increase application accuracy (Guo et al., 2018; He et al., 2018). The WEI constructed in this study provided high estimation accuracy $\left(R^{2}=0.623\right)$ within a range of $-20-10^{\circ}$, and compared with the optimal angle $\left(-10^{\circ}\right)$, the estimation accuracy of WEI within a range of $-20-10^{\circ}$ decreased by only $1.93 \%$, while the RMSE value increased by only $4.71 \%$. These results suggest that the WEI reduces the sensitivity to observation angles within the range of $-20-10^{\circ}$, helping establish a more unified monitoring model, and increasing the efficiency and applicability of portable monitors in the field. However, despite these findings, this experiment was carried out using only three winter wheat varieties under two ecological conditions, and therefore, further analysis of the monitoring model in other regions, and with different crop types and varieties is required.

\section{CONCLUSION}

Real-time monitoring of crop water use is of great significance in improving crop irrigation management and guiding water-saving agricultural production. Based on the WUE, this study adopted 


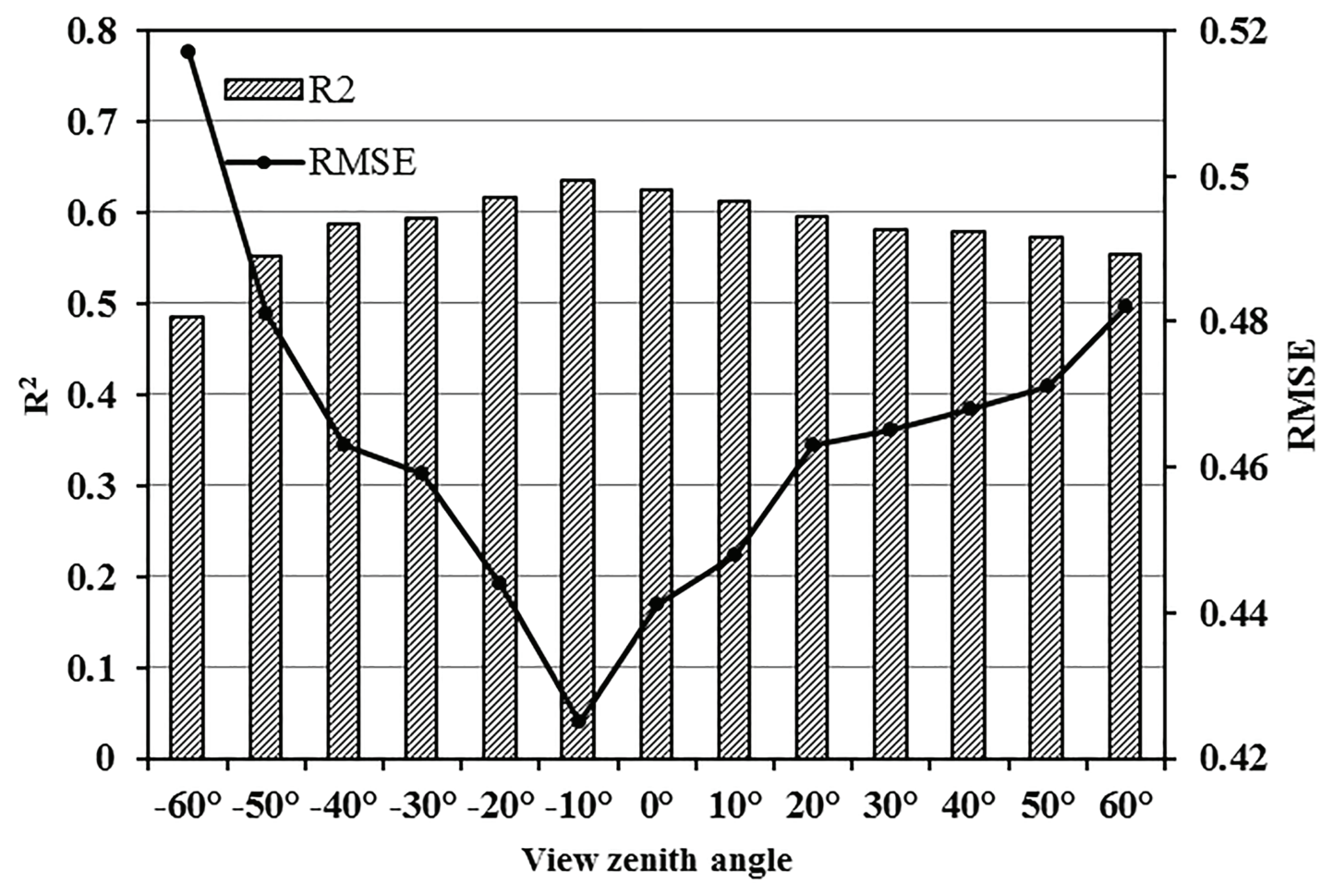

FIGURE 6 | Correlations between water efficiency index (WEI) and WUE at different zenith angles $(n=140)$.

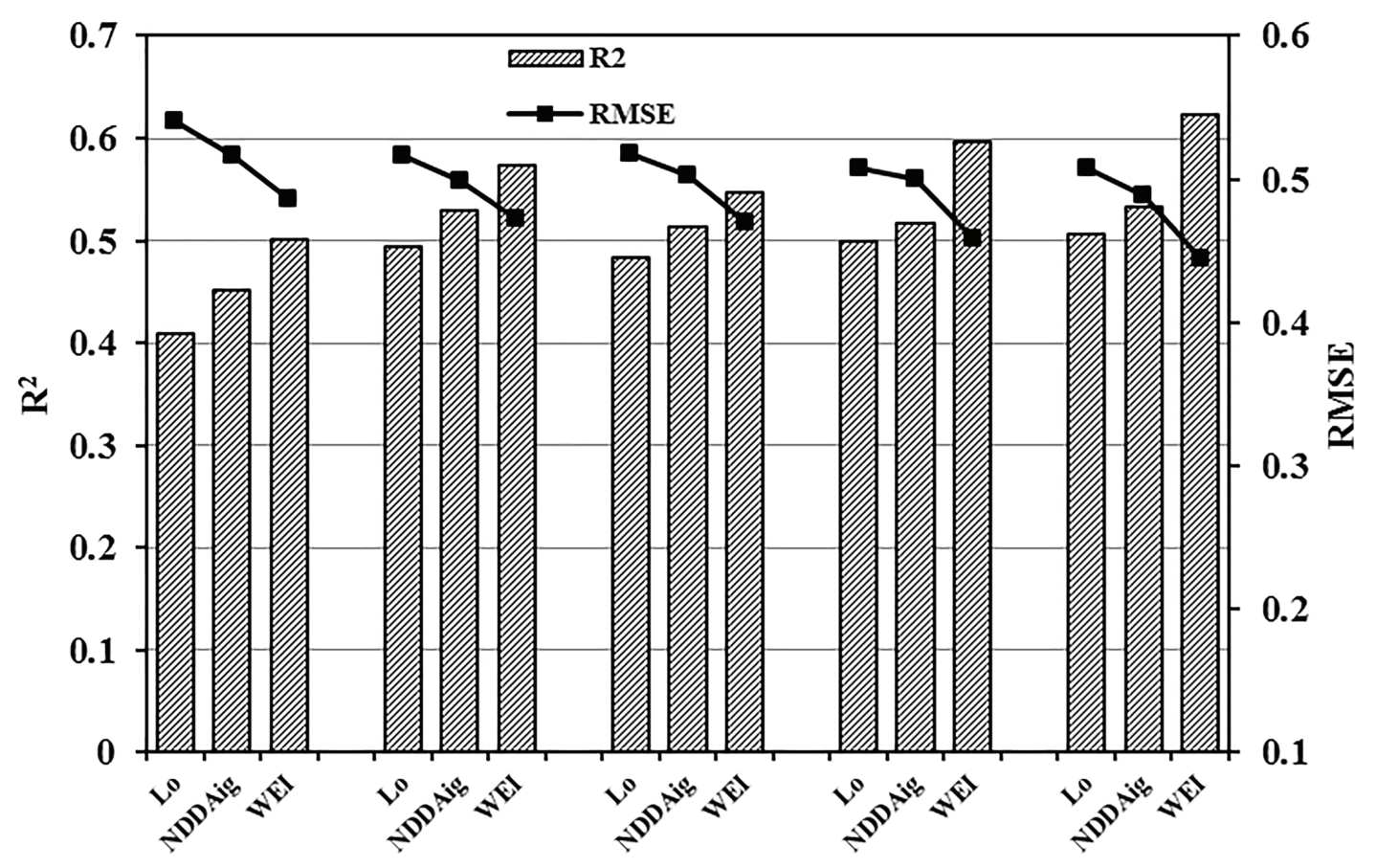

FIGURE 7 | Comparisons of the predictive abilities of Lo, NDDAig, and WEl within five zenith angle ranges $\left(-60-60^{\circ},-60-0^{\circ}, 0-60^{\circ},-20-20^{\circ}\right.$, and $\left.-20-10^{\circ}\right)$ with respect to WUE $(n=140)$. 

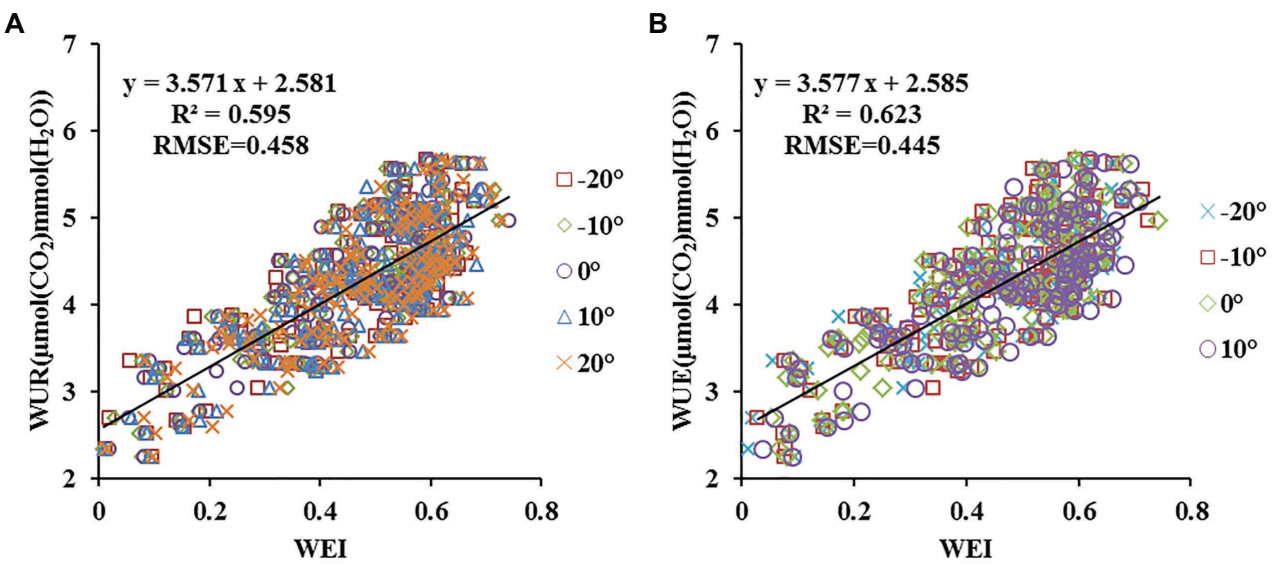

FIGURE 8 | Comparisons of the predictive power of WEl at different view zenith angles (VZAs) combinations in terms of WUE (A: $n=700 ; \mathbf{B}: n=560)$.
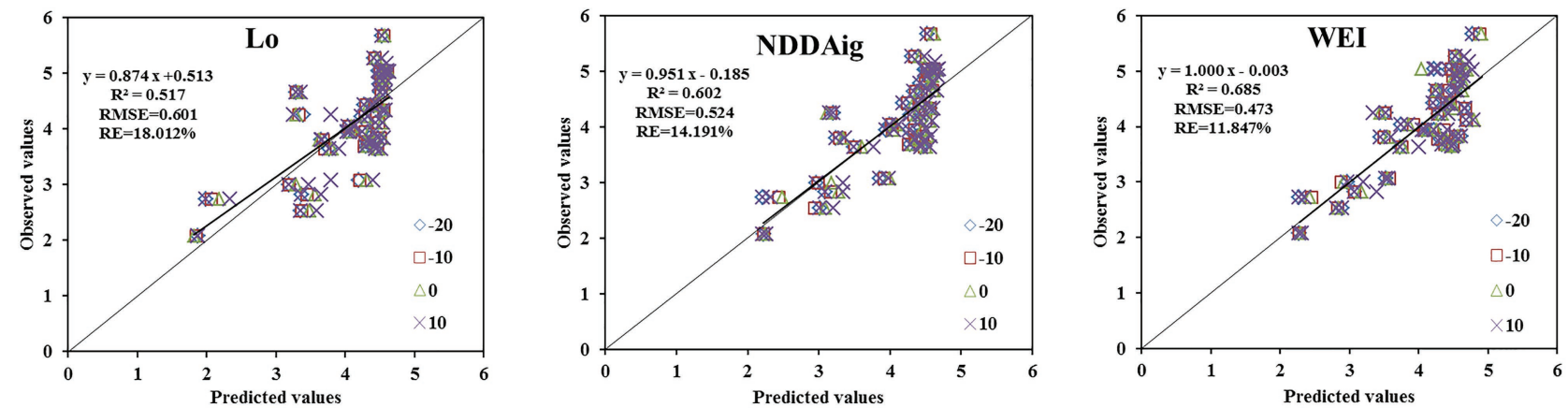

FIGURE 9 | Comparisons between predicted and measured WUE based on Lo, NDDAig, and WEl at a zenith angle of $-20^{\circ}$ to $+10^{\circ}(n=120)$.

a combined vegetation index method, using NDDAig/FWBI to effectively determine the WUE of winter wheat leaves reflecting a new index named the WEI. The WEI performed better than other common vegetation indexes at 13 observation angles, with the most suitable observation range falling between -20 and $10^{\circ}$. Within this range, a unified estimation model was established with reduced dependency on observation angle limitations. These findings provide a basis for the selection of varieties with a high WUE as well as supporting water-saving cultivation management.

\section{DATA AVAILABILITY STATEMENT}

The raw data supporting the conclusions of this article will be made available by the authors, without undue reservation.

\section{REFERENCES}

Baret, F., and Guyot, G. (1991). Potentials and limits of vegetation indices for LAI and APAR assessment. Remote Sens. Environ. 35, 161-173. doi: 10.1016/0034-4257(91)90009-U

\section{AUTHOR CONTRIBUTIONS}

$\mathrm{H}-\mathrm{YZ}, \mathrm{C}-\mathrm{YW}$ and WF conceived the research concept; H-YZ, M-RL, LS and XL performed the experiments; H-YZ, C-YW wrote the paper; Z-HF and W-DL contributed to the results analysis and discussion.

\section{FUNDING}

This work was supported by the National Key Research and Development Program of China (Grant No. 2018YFD0300707) and the Fund for Modern Agro-industry System of Henan province (S2010-01-G07). National Natural Science Foundation of China (31671624).

Barnes, B. B., and Hu, C. (2016). Dependence of satellite ocean color data products on viewing angles: a comparison between SeaWiFS, MODIS, and VIIRS. Remote Sens. Environ. 175, 120-129. doi: 10.1016/j.rse.2015.12.048 Bastiaanssen, W. G. M., Thiruvengadachari, S., Sakthivadivel, R., and Molden, D. J. (1999). Satellite remote sensing for estimating productivities of land and 
water. Int. J. Water Resour. Dev. 15, 181-194. doi: 10.1080/0790062994 9005

Carter, G. A. (1991). Primary and secondary effects of water content on the spectral reflectance of leaves. Am. J. Bot. 78, 916-924. doi: 10.1002/j.1537-2197.1991.tb 14495.x

Chen, J. M., Liu, J., Leblanc, S. G., Lacaze, R., and Roujean, J. L. (2003). Multi-angular optical remote sensing for assessing vegetation structure and carbon absorption. Remote Sens. Environ. 84, 516-525. doi: 10.1016/ S0034-4257(02)00150-5

Chen, J. M., Menges, C. H., and Leblanc, S. G. (2005). Global mapping of foliage clumping index using multi-angular satellite data. Remote Sens. Environ. 97, 447-457. doi: 10.1016/j.rse.2005.05.003

Chopping, M. J., Rango, A., Havstad, K. M., Schiebe, F. R., Ritchie, J. C., Schmugge, T. J., et al. (2003). Canopy attributes of desert grassland and transition communities derived from multiangular airborne imagery. Remote Sens. Environ. 85, 339-354. doi: 10.1016/S0034-4257(03)00012-9

Cierniewski, J., Gdala, T., and Karnieli, A. (2004). A hemispherical-directional reflectance model as a tool for understanding image distinctions between cultivated and uncultivated bare surfaces. Remote Sens. Environ. 90, 505-523. doi: 10.1016/j.rse.2004.01.004

Condon, A. G., Richards, R. A., Rebetzke, G. J., and Farquhar, G. D. (2002). Improving intrinsic water-use efficiency and crop yield. Crop Sci. 42, 122-131. doi: $10.2135 /$ cropsci2002.1220

Curran, P. J. J. R. S. o. E. (1989). Remote sensing of foliar chemistry. Remote Sens. Environ. 30, 271-278. doi: 10.1016/0034-4257(89)90069-2

Daughtry, C. S. T., Walthall, C. L., Kim, M. S., De Colstoun, E. B., and Mcmurtrey, J. E. (2000). Estimating corn leaf chlorophyll concentration from leaf and canopy reflectance. Remote Sens. Environ. 74, 229-239. doi: 10.1016/ S0034-4257(00)00113-9

Dawson, T. P., Curran, P. J., North, P. R. J., and Plummer, S. E. (1999). The propagation of foliar biochemical absorption features in forest canopy reflectance: a theoretical analysis. Remote Sens. Environ. 67, 147-159. doi: 10.1016/S0034-4257(98)00081-9

Diner, D. J., Asner, G. P., Davies, R., Knyazikhin, Y., Muller, J. P., Nolin, A. W., et al. (1999). New directions in earth observing: scientific applications of multiangle remote sensing. B. Am. Meteorol. Soc. 80, 2209-2228. doi: 10.1175/1520-0477(1999)080<2209:ndieos >2.0.co;2

Dobrowski, S. Z., Pushnik, J. C., Zarco-Tejada, P. J., and Ustin, S. L. (2005). Simple reflectance indices track heat and water stress-induced changes in steady-state chlorophyll fluorescence at the canopy scale. Remote Sens. Environ. 97, 403-414. doi: 10.1016/j.rse.2005.05.006

Dong, B., Shi, L., Shi, C. h., Qiao, Y. Z., Liu, M. Y., and Zhang, Z. B. (2011). Grain yield and water use efficiency of two types of winter wheat cultivars under different water regimes. Agr. Water Manage. 99, 103-110. doi: 10.1016/j. agwat.2011.07.013

Drolet, G. G., Middleton, E. M., Huemmrich, K. F., Hall, F. G., Amiro, B. D., Barr, A. G., et al. (2008). Regional mapping of gross light-use efficiency using MODIS spectral indices. Remote Sens. Environ. 112, 3064-3078. doi: 10.1016/j.rse.2008.03.002

Fitzgerald, G. J., Rodriguez, D., Christensen, L. K., Belford, R., Sadras, V. O., and Clarke, T. R. (2006). Spectral and thermal sensing for nitrogen and water status in rainfed and irrigated wheat environments. Precis. Agric. 7, 233-248. doi: 10.1007/s11119-006-9011-Z

Feng, W., Guo, B.-B., Wang, Z.-J., He, L., Song, X., Wang, Y.-H., et al. (2014). Measuring leaf nitrogen concentration in winter wheat using double-peak spectral reflection remote sensing data. Field Crop. Res. 159, 43-52. doi: $10.1016 /$ j.fcr.2014.01.010

Galvão, L. S., Roberts, D. A., Formaggio, A. R., Numata, I., and Breunig, F. M. (2009). View angle effects on the discrimination of soybean varieties and on the relationships between vegetation indices and yield using off-nadir Hyperion data. Remote Sens. Environ. 113, 846-856. doi: 10.1016/j.rse.2008. 12.010

Gamon, J. A., Peñuelas, J., and Field, C. B. (1992). A narrow-waveband spectral index that tracks diurnal changes in photosynthetic efficiency. Remote Sens. Environ. 41, 35-44. doi: 10.1016/0034-4257(92)90059-S

Garbulsky, M. F., Peñuelas, J., Gamon, J., Inoue, Y., and Filella, I. (2011). The photochemical reflectance index (PRI) and the remote sensing of leaf, canopy and ecosystem radiation use efficiencies: a review and meta-analysis. Remote Sens. Environ. 115, 281-297. doi: 10.1016/j.rse.2010.08.023
Gitelson, A. A., Gamon, J. A., and Solovchenko, A. (2017). Multiple drivers of seasonal change in PRI: implications for photosynthesis 2. Stand level. Remote Sens. Environ. 190, 198-206. doi: 10.1016/j.rse.2016.12.015

Gitelson, A. A., Kaufman, Y. J., Stark, R., and Rundquist, D. (2002). Novel algorithms for remote estimation of vegetation fraction. Remote Sens. Environ. 80, 76-87. doi: 10.1016/S0034-4257(01)00289-9

Guo, B. B., Zhu, Y. J., Feng, W., He, L., Wu, Y. P., Zhou, Y., et al. (2018). Remotely estimating aerial $\mathrm{N}$ uptake in winter wheat using red-edge area index from multi-angular hyperspectral data. Front. Plant Sci. 9:675. doi: 10.3389/fpls.2018.00675

Haboudane, D., Miller, J. R., Tremblay, N., Zarco-Tejada, P. J., and Dextraze, L. (2002). Integrated narrow-band vegetation indices for prediction of crop chlorophyll content for application to precision agriculture. Remote Sens. Environ. 81, 416-426. doi: 10.1016/S0034-4257(02)00018-4

Hall, F. G., Hilker, T., Coops, N. C., Lyapustin, A., Huemmrich, K. F., Middleton, E. M., et al. (2008). Multi-angle remote sensing of forest light use efficiency by observing PRI variation with canopy shadow fraction. Remote Sens. Environ. 112, 3201-3211. doi: 10.1016/j.rse. 2008.03.015

Hatfield, J. L., Gitelson, A. A., Schepers, J. S., and Walthall, C. L. (2008). Application of spectral remote sensing for agronomic decisions. Agron. J. 100, 117-131. doi: 10.2134/agronj2006.0370c

He, L., Coburn, C. A., Wang, Z. J., Feng, W., and Guo, T. C. (2018). Reduced prediction saturation and view effects for estimating the leaf area index of winter wheat. IEEE. Trans. Geosci. Remote Sens. 57, 1637-1652. doi: 10.1109/ TGRS.2018.2868138

He, L., Song, X., Feng, W., Guo, B. B., Zhang, Y. S., Wang, Y. H., et al. (2016). Improved remote sensing of leaf nitrogen concentration in winter wheat using multi-angular hyperspectral data. Remote Sens. Environ. 174, 122-133. doi: $10.1016 /$ j.rse.2015.12.007

He, L., Zhang, H. Y., Zhang, Y. S., Song, X., and Guo, T. C. (2015). Estimating canopy leaf nitrogen concentration in winter wheat based on multi-angular hyperspectral remote sensing. Eur. J. Agron. 73, 170-185. doi: 10.1016/j. eja.2015.11.017

Huang, W. J., Wang, Z. J., Huang, L. S., Lamb, D. W., Ma, Z. H., Zhang, J. C., et al. (2011). Estimation of vertical distribution of chlorophyll concentration by bi-directional canopy reflectance spectra in winter wheat. Precis. Agric. 12, 165-178. doi: 10.1007/s11119-010-9166-5

Huete, A., Didan, K., Miura, T., Rodriguez, E. P., Gao, X., and Ferreira, L. G. (2002). Overview of the radiometric and biophysical performance of the MODIS vegetation indices. Remote Sens. Environ. 83, 195-213. doi: 10.1016/ S0034-4257(02)00096-2

Hultine, K. R., and Marshall, J. D. (2000). Altitude trends in conifer leaf morphology and stable carbon isotope composition. Oecologia 123, 32-40. doi: $10.1007 / \mathrm{s} 004420050986$

Jordan, C. F. (1969). Derivation of leaf-area index from quality of light on the forest floor. Ecolo. Soc. Am. 50, 663-666. doi: 10.2307/1936256

Ju, C. H., Tian, Y. C., Yao, X., Cao, W. X., Zhu, Y., and Hannaway, D. J. P. (2010). Estimating leaf chlorophyll content using red edge parameters. Pedosphere 20, 633-644. doi: 10.1016/S1002-0160(10)60053-7

Kimes, D. S., Newcomb, W. W., Tucker, C. J., Zonneveld, I. S., Wijngaarden, V. W., Leeuw, D. J., et al. (1985). Directional reflectance factor distribution for cover types of northern Africa in NOAA 7/8 AVHRR bands 1 and 2. Remote Sens. Environ. 18, 1-19. doi: 10.1016/0034-4257(85)90034-3

Leblanc, S. G., Chen, J. M., White, H. P., Latifovic, R., Lacaze, R., and Roujean, J. L. (2005). Canada-wide foliage clumping index mapping from multiangular POLDER measurements. Can. J. Remote. Sens. 31, 364-376. doi: $10.5589 / \mathrm{m} 05-020$

Li, F., Liu, L. Y., Wang, J. H., Li, L. X., Zhao, C. J., and Cao, W. X. (2005) Detection of nitrogen status in FCV tobacco leaves with the spectral reflectance. IEEE International Geoscience \& Remote Sensing Symposium. 1863-1866.

Merzlyak, M. N., Gitelson, A. A., Chivkunova, O. B., and Rakitin, V. Y. (1999). Non-destructive optical detection of pigment changes during leaf senescence and fruit ripening. Physiol. Plant. 106, 135-141. doi: 10.1034/j.13993054.1999.106119.x

Middleton, E. M., Huemmrich, K. F., Cheng, Y.-B., and Margolis, H. A. (2011). "Spectral bioindicators of photosynthetic efficiency and vegetation stress" in Hyperspectral remote sensing of vegetation. eds. P. S. Thenkabail, J. G. Lyon, A. Huete (Boca Raton, FL, USA: CRC Press), 265-288. 
Miller, J. R., Hare, E. W., and Wu, J. (1990). Quantitative characterization of the vegetation red edge reflectance 1 . An inverted-gaussian reflectance model. Int. J. Remote Sens. 11, 1755-1773. doi: 10.1080/01431169008955128

Mistele, B., and Schmidhalter, U. (2008). Estimating the nitrogen nutrition index using spectral canopy reflectance measurements. Eur. J. Agron. 29, 184-190. doi: 10.1016/j.eja.2008.05.007

Peñuelas, J., Baret, F., and Filella, I. (1995a). Semiempirical indexes to assess carotenoids chlorophyll-a ratio from leaf spectral reflectance. Photosynthetica 1995, 221-230. doi: 10.1007/BF00029464

Peñuelas, J., Filella, I., Biel, C., Serrano, L., and Save, R. (1993a). The reflectance at the $950-970 \mathrm{~nm}$ region as an indicator of plant water status. Int. J. Remote Sens. 14, 1887-1905. doi: 10.1080/01431169308954010

Peñuelas, J., Filella, I., Lloret, P., Oz, F. M., and Vilajeliu, M. (1995b). Reflectance assessment of mite effects on apple trees. Int. J. Remote Sens. 16, 2727-2733. doi: $10.1080 / 01431169508954588$

Peñuelas, J., Gamon, J. A., Griffin, K. L., and Field, C. B. (1993b). Assessing community type, plant biomass, pigment composition, and photosynthetic efficiency of aquatic vegetation from spectral reflectance. Remote Sens. Environ. 46, 110-118. doi: 10.1016/0034-4257(93)90088-F

Peñuelas, J., Pinol, J., Ogaya, R., and Filella, I. (1997). Estimation of plant water concentration by the reflectance water index WI $\left(\mathrm{R}_{900} / \mathrm{R}_{970}\right)$. Int. J. Remote Sens. 18, 2869-2875. doi: 10.1080/014311697217396

Pinol, J., Filella, I., Ogaya, R., and Penuelas, J. (1998). Ground-based spectroradiometric estimation of live fine fuel moisture of Mediterranean plants. Agric. For. Meteorol. 90, 173-186. doi: 10.1016/S0168-1923(98)00053-7

Pocewicz, A., Vierling, L. A., Lentile, L. B., and Smith, R. (2007). View angle effects on relationships between MISR vegetation indices and leaf area index in a recently burned ponderosa pine forest. Remote Sens. Environ. 107, 322-333. doi: 10.1016/j.rse.2006.06.019

Rautiainen, M., Stenberg, P., Nilson, T., and Kuusk, A. (2004). The effect of crown shape on the reflectance of coniferous stands. Remote Sens. Environ. 89, 41-52. doi: 10.1016/j.rse.2003.10.001

Read, J. J., Tarpley, L., Mckinion, J. M., and Reddy, K. R. (2002). Narrowwaveband reflectance ratios for remote estimation of nitrogen status in cotton. J. Environ. Qual. 31, 1442-1452. doi: 10.2134/jeq2002.1442

Richards, R. A. (2006). Physiological traits used in the breeding of new cultivars for water-scarce environments. Agr. Water Manage. 80, 197-211. doi: 10.1016/j. agwat.2005.07.013

Roujean, J. L., and Breon, F. M. (1995). Estimating PAR absorbed by vegetation from bidirectional reflectance measurements. Remote Sens. Environ. 51, 375-384. doi: 10.1016/0034-4257(94)00114-3

Rouse, J. W., Haas, R. W., Schell, J. A., Deering, D. W., and Harlan, J. C. (1974). Monitoring the vernal advancement and retrogradation (Greenwave Effect) of natural vegetation. NASA/GSFCT Type III Final Rep. 75-80.

Santos, P., and Negri, A. J. (1997). A comparison of the normalized difference vegetation index and rainfall for the amazon and northeastern Brazil. J. Appl. Meteorol. 36, 958-965. doi: 10.1175/1520-0450(1997)036<0958:AC OTND $>2.0 . \mathrm{CO} ; 2$

Sheshbahreh, M. J., Dehnavi, M. M., Salehi, A., and Bahreininejad, B. (2019). Effect of irrigation regimes and nitrogen sources on biomass production, water and nitrogen use efficiency and nutrients uptake in coneflower (Echinacea purpurea L.). Agr. Water Manage. 213, 358-367. doi: 10.1016/j.agwat.2018.10.011

Shibayama, M., and Wiegand, C. L. (1985). View azimuth and zenith, and solar angle effects on wheat canopy reflectance. Remote Sens. Environ. 18, 91-103. doi: 10.1016/0034-4257(85)90040-9

Sims, D. A., and Gamon, J. A. (2002). Relationships between leaf pigment content and spectral reflectance across a wide range of species, leaf structures and developmental stages. Remote Sens. Environ. 81, 337-354. doi: 10.1016/ S0034-4257(02)00010-X

Sims, D. A., and Gamon, J. A. (2003). Estimation of vegetation water content and photosynthetic tissue area from spectral reflectance: a comparison of indices based on liquid water and chlorophyll absorption features. Remote Sens. Environ. 84, 526-537. doi: 10.1016/S0034-4257(02)00151-7

Stagakis, S., Markos, N., Sykioti, O., and Kyparissis, A. (2010). Monitoring canopy biophysical and biochemical parameters in ecosystem scale using satellite hyperspectral imagery: an application on a Phlomis fruticosa
Mediterranean ecosystem using multiangular CHRIS/PROBA observations. Remote Sens. Environ. 114, 977-994. doi: 10.1016/j.rse.2009.12.006

Strachan, I. B., Pattey, E., and Boisvert, J. B. (2002). Impact of nitrogen and environmental conditions on corn as detected by hyperspectral reflectance. Remote Sens. Environ. 80, 213-224. doi: 10.1016/S0034-4257(01)00299-1

Thenkabail, P. S., Smith, R. B., and Pauw, E. D. (2000). Hyperspectral vegetation indices and their relationships with agricultural crop characteristics. Remote Sens. Environ. 71, 158-182. doi: 10.1016/S0034-4257(99)00067-X

Thomas, J. R., Namken, L. N., Oerther, G. F., and Brown, R. G. (1971). Estimating leaf water content by reflectance measurements. Agron. J. 63, 845-847. doi: 10.2134/agronj1971.00021962006300060007x

Tian, Y. C., Yao, X., Yang, J., Cao, W. X., Hannaway, D. B., and Zhu, Y. (2011). Assessing newly developed and published vegetation indices for estimating rice leaf nitrogen concentration with ground- and space-based hyperspectral reflectance. Field Crop Res. 120, 299-310. doi: 10.1016/j.fcr.2010.11.002

Tian, Y. C., Zhu, Y., and Cao, W. X. (2005). Monitoring leaf photosynthesis with canopy spectral reflectance in rice. Photosynthetica 43, 481-489. doi: 10.1007/s11099-005-0078-y

Wang, W., Yao, X., Yao, X. F., Tian, Y. C., Liu, X. J., Ni, J., et al. (2012). Estimating leaf nitrogen concentration with three-band vegetation indices in rice and wheat. Field Crop Res. 129, 90-98. doi: 10.1016/j.fcr.2012.01. 014

Wolfe, D. W., Henderson, D. W., Hsiao, T. C., and Alvino, A. (1988). Interactive water and nitrogen effects on senescence of maize. II. Photosynthetic decline and longevity of individual leaves. Agron. J. 80, 865-870. doi: 10.2134/agr onj1988.00021962008000060005x

Yao, X., Jia, W. Q., Si, H. Y., Guo, Z. Q., Tian, Y. C., Liu, X. J., et al. (2014). Exploring novel bands and key index for evaluating leaf equivalent water thickness in wheat using hyperspectra influenced by nitrogen. PLoS One 9:e96352. doi: 10.1371/journal.pone.0096352

Yu, G. R., Zhuang, J., and Yu, Z. L. (2001). An attempt to establish a synthetic model of photosynthesis-transpiration based on stomatal behavior for maize and soybean plants grown in field. J. Plant Physiol. 158, 861-874. doi: 10.1078/0176-1617-00177.

Zarco-Tejada, P. J., González-Dugo, V., Williams, L. E., Suárez, L., Berni, J. A. J., Goldhamer, D., et al. (2013). A PRI-based water stress index combining structural and chlorophyll effects: assessment using diurnal narrow-band airborne imagery and the CWSI thermal index. Remote Sens. Environ. 138, 38-50. doi: 10.1016/j.rse.2013.07.024

Zarco-Tejada, P. J., Rueda, C. A., and Ustin, S. L. (2003). Water content estimation in vegetation with MODIS reflectance data and model inversion methods. Remote Sens. Environ. 85, 109-124. doi: 10.1016/S0034-4257(02) 00197-9

Zhang, D. Y., Coburn, C., Zhao, J. L., Wang, X., Wang, Z. J., and Liang, D. (2013) Chlorophyll Density Inversion of Soybean Canopy Based on Multiangle Imaging Hyperspectral Data. 44, 205-213 Transactions of the Chinese Society for Agricultural Machinery (in Chinese with English abstract).

Zhang, H. Y., Ren, X. X., Zhou, Y., Wu, Y. P., He, L., Heng, Y. R., et al. (2018). Remotely assessing photosynthetic nitrogen use efficiency with in situ hyperspectral remote sensing in winter wheat. Eur. J. Agron. 101, 90-100. doi: 10.1016/j.eja.2018.08.010

Zhang, Z. B., Shao, H. B., Xu, P., Chu, L. Y., Lu, Z. H., and Tian, J. Y. (2007). On evolution and perspectives of bio-watersaving. Colloid. Surface. B. 55, 1-9. doi: $10.1016 /$ j.colsurfb.2006.10.036

Conflict of Interest: The authors declare that the research was conducted in the absence of any commercial or financial relationships that could be construed as a potential conflict of interest.

Copyright (c) 2021 Zhang, Liu, Feng, Song, Li, Liu, Wang and Feng. This is an open-access article distributed under the terms of the Creative Commons Attribution License (CC BY). The use, distribution or reproduction in other forums is permitted, provided the original author(s) and the copyright owner(s) are credited and that the original publication in this journal is cited, in accordance with accepted academic practice. No use, distribution or reproduction is permitted which does not comply with these terms. 